\title{
Empowering Teachers of Cultural Arts of SMA 2 in Payakumbuh in Arranging Song/Music Using the Noteworthy Composer of Music Program
}

\author{
Yos Sudarman ${ }^{1, *}$ Esy Maestro ${ }^{1}$ Susmiarti Susmiarti ${ }^{1}$ \\ ${ }^{1}$ Drama, Dance and Music Program, Uiversitas Negeri Padang, Padang, Indonesia \\ *Corresponding author. Email: sudarmansendra@fbs.unp.ac.id
}

\begin{abstract}
This article aims to provide an explanation of the empowering the teachers of cultural arts of SMA 2 in Payakumbuh through the provision of knowledge and skills about writing song/music arrangements using program of he noteworthy composer. As a knowledge, this program is introduced to teachers of arts and culture as a standard song or music writing using block notation. Meanwhile, as a skill, this music program is used as training material to make song/music arrangements, which can then be used as teaching materials for music lessons at school. The method used is an indirect/direct virtual practice method and continuous face-to-face, where teachers immediately practice arranging songs on a computer/laptop for two virtual meetings and one face-to-face meeting. The results showed that the use of program of the noteworthy composer, which was introduced and practiced in the practice of arranging songs, was effective in helping teachers develop music learning materials in schools in the form of simple song/music arrangements. Apart from being easy to use, the song/music arrangements produced meet the standards for writing music notation in the arrangement of products that can be displayed directly on the computer, printed, or stored in MIDI file data which can be an example of making and developing music teaching materials for music lessons at school.
\end{abstract}

Keywords: Noteworthy Composer, Song/Music Arrangement, Music Notation

\section{INTRODUCTION}

Cultural arts teachers in schools such as teachers who teach music at high schools in Payakumbuh city, West Sumatra province, are often faced with the problem of scarcity of teaching materials in the form of songs, because many of the teaching materials that serve as examples come from old or outdated sources. Moreover, teaching materials commonly used for singing and playing music practice lessons still use numerical notation which is considered non-standard notation. While the subject matter requires examples of songs in block notation. There is a difference between the subject matter of songs/music, some of which have used block notation but some still use number notation, causing the learning process in its activities and the learning outcomes of music achieved by students to be out of sync. This problem actually occurs in learning the art of music which is cared for by art and culture teachers at the high school level in the city of Payakumbuh.
Moreover, the implementation of music learning in schools during the COVID-19 pandemic has encouraged teachers to try to recognize more uses of music programs that can be used to create and publish teaching materials directly in the form of song arrangements. The noteworthy composer program version 2 which is full version is one of the music programs for writing music/song notation which is actually not widely known by teachers, but can be used as a means to solve the problem of making and direct publication of teaching materials in the form of musical arrangements in music learning in Indonesia. school. By carrying out the practice of making song arrangements using this music program, the service team would like to introduce the noteworthy composer program as a form of empowering teachers to have knowledge of music programs and at the same time apply it in the practice of making song/music arrangement teaching materials. Moreover, at the same time nowadays, whether they are told by the teacher or not, on the other hand, school students are also starting to get used to self-study during this 
pandemic to learn music from online sources. This independent student learning activity to learn music online will also question the teacher's insight and skills about music programs, especially in making song/music arrangements using a music computer program. From the facts of initial observations in the field, it is known that some of the art and culture teachers who teach at high schools in Payakumbuh City at this time, there are those who do not have knowledge about music programs and how to use them. Especially for some teachers who do not have a background in the discipline of music education, but they are still required to be able to teach music which is known as a cognate part of cultural arts lessons, whose scientific design is multidisciplinary in schools. For this reason, the service team is trying to introduce the noteworthy composer music program, which is considered a music program that is simpler than other notation writing programs, which allows art and culture teachers who do not have a background in music education to easily apply it in making song arrangement teaching materials. simple at school.

\section{METHOD}

This community partnership activity is carried out by applying the practice method directly/indirectly but continuously. It is said to be a direct/indirect training method, because teachers who are familiar with the noteworthy composer program as one of the notation/agu writing programs with block notation, are directly empowered to practice it on computers that have the program installed. However, the implementation of the exercise is guided indirectly (online), namely by providing virtual training in the first two meetings using a video conference application using the Zoom application.

Then it is said to be a continuous training method, because teachers who have known and started practicing using the noteworthy composer program since they were first introduced to making song/music arrangement teaching materials at the initial two virtual meetings, continue to be monitored continuously until the last practice meeting. . So the practice of making simple song arrangements with the noteworthy composer program in this service activity was carried out in two virtual meetings and one face-to-face meeting.

\section{RESULTS AND DISCUSSION}

\subsection{Introduction Noteworthy Composer Program}

The main problem that often arises when teachers teach music at high schools in Payakumbuh City is in the manufacture of newer teaching materials with contemporary models, so that teaching materials are synchronous with the use of standard notation (beam notation) for arrangements that adapt to needs. learn to teach at school.

Although in today's technological developments, there are already many music notation programs that can be used by teachers and students to write songs/music in block notation, the service team is interested in introducing the full version 2 noteworthy composer program, which has been periodically developed by the creators. since it was first released in 1994 at www.noteworthysoftware.com.

Following the development of the program that was impacted by the release of the noteworthy composer v. 2 full version program, users have been able to record music audio, edit it, and print it on standard music notation derived from notation writing (score) based on block notation. Moreover, with this program it is also easy to perform basic tone transpose and instrument transpose (tone transpose and ionstrument transpose) quickly. This program also provides a feature to publish written music as a new creation or arrangement of songs/music directly on the internet from arranged works on a computer/laptop. Then the work of creation and arrangement of songs/music which will later become teacher assets can also be stored instead of being published in standard MIDI data files that can be used in other MIDI applications.

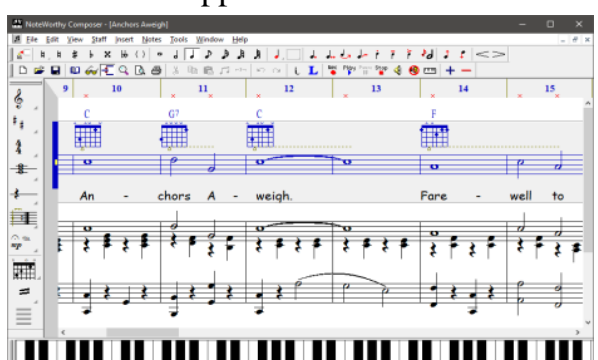

|| III || ||| || ||| || ||| || ||| || |||

Figure 1 "The desktop view of program of The Noteworthy Composer computer version 2 (full version) 
Based on the considerations in the simplicity of features and the ease of operation of this music program, it has become one of the initial considerations for many users from various professions to be interested in using the Noteworthy Composer v.2 program, including users from arts and culture teachers in Payakumbuh City who are members of the training. writing song/music notation in teaching materials for song/music arrangement for learning the art of music at school.

\subsection{Results of Exercise Activities Making Song/music Arrangements}

\subsubsection{First Meeting Results (Virtual)}

At the First Meeting virtually; teachers are given knowledge by using the lecture method about the composer's noteworthy program as an introduction to music notation writing programs with simple and easyto-operate features on a computer, which can be used to make teaching materials in music lessons in the form of song/music arrangements. At this first meeting, the service team introduced examples of arrangements for children's songs or national compulsory songs that could be made with this program, such as the arrangement for the song "Bungaku, created by C. Simanjuntak". The arrangement that is exemplified is a form of two-voice song arrangement, as well as a song arrangement that uses a piano instrument as an accompaniment. The result of the virtual meeting at this first meeting was the interest of the trainee teachers to start trying to use the noteworthy composer program to try to start practicing the song/music arrangement they wanted to make.

\subsubsection{Results of the Second Meeting (Virtual)}

At the Second Meeting virtually, the trainee teachers started dealing with their respective computers at home and at school, which they had installed with the noteworthy composer program based on the installation manual that had been given in advance in the form of a manual. Because each teacher training participant has a different technical background on operating a computer that has this program installed, the speed and absorption of each teacher is also different for this training material. This is where the use of the question and answer method and discussion occurs between teachers who are already able to operate it and teachers who are still at the stage of learning to operate the program. In the end, all the trainee teachers were able to recognize the details of the program's features and functions that could be used to create a series of tones, motifs, and melodies, as well as the design of musical instruments in the songs/music that they arranged. The results obtained from the virtual meeting at this second meeting were the ability of teachers to be able to display examples of their own song/music arrangements directly from each teacher's computer/laptop, which had also been presented by video conference in the Zoom application. Even though the arrangements displayed online, there are still variations between works that are almost finished and those that are still in the process of being worked on.

\subsubsection{Results of the Second Meeting (Face-to- Face)}

At the Third Meeting face-to-face, the service team directly met face-to-face and carried out training at the location of service activities, namely at SMA Negeri 1 Payakumbuh City, which is also one of the locations for the Payakumbuh Arts and Culture Teacher Consultation (MGMP). Accompanied by the chairman of the Payakumbuh City Arts and Culture MGMP, the service team tried to provide direct training (practice method) to teachers. Starting with the lecture method explaining the results of virtual meetings 1 and 2 , at meeting 3 the emphasis was more on the practice method using the noteworthy composer program for song arrangements that had previously been done by the teachers. Whether teachers have arranged two or more voices, or have arranged songs with accompanying music, both of them are equally empowered by this exercise. Several technical problems in the operation of the noteworthy composer program and the technical composition of the song/music arrangement have been overcome by the service team and the trainees, because some teachers who already understand the technique of using the program and the technique of arranging songs/music can provide technical assistance in a tutorial. peers (peer tutors) to other teachers who have not been able. All the instructions and directions given by peer tutors by peer teachers are also based on the results of direct consultation with the service team who provided this training. The result of the face-to-face meeting at this third meeting was the success of the teacher in making song arrangements or music arrangements in the form of finished products, arranging songs/music for different works from each arranger (teachers who arranged). The finished product of this song/music arrangement can be displayed as a printed (print-out) sheet of song/music notation text, as well as a song/music arrangement that can be played directly on the computer according to the notation displayed on the desktop screen, including song/music arrangements. as masterpieces of music that can be stored in MIDI file data. The service team and the training teachers agreed that the finished product of the 
song/music arrangements made by the trainee teachers could later be published on the internet for use by other users. Or at least it can be displayed directly on a computer for review, printed, or stored in a MIDI file data which can be further modified at a later time, as one of the assets, for example song/music arrangements which are the development of music teaching materials for music lessons in schools that has met the standards of writing music using block notation.

\section{CONCLUSIONS AND SUGGESTIONS}

Based on training activities to empower teachers to empower high school cultural arts teachers in Payakumbuh in arranging songs using this noteworthy composer program, it can be concluded that with this program, teachers can make simple music teaching materials in the form of two or more voice song arrangements., and song arrangements with musical accompaniment instruments, which are made easier and faster. This conclusion was obtained because when teachers made song/music arrangements, they were introduced to the noteworthi composer program as an alternative program for writing music notation which was simpler, so that when they were given direct practice in using it, they did not find many obstacles both in terms of operating techniques for this program on a computer. as well as in terms of song/music arrangement techniques. By using lecture methods, discussions, exercises, as well as the assistance of peer tutors, teachers can make finished products of song/music arrangements made by the trainee teachers as their own work. By using this noteworthy composer v. 2 program, the arranged works of these teachers can be published on the internet for other users, or at least can be broadcast live on the teacher's computer for review. The service team recommends teachers who are already able to use this noteworthy composer program, so that their song/music arrangement works at least can be printed or stored in MIDI file data that can be remodified in the future, as a finished work for example creation and development. music teaching materials in schools that already meet the standards of music writing using block notation.

\section{ACKNOWLEDGMENTS}

Thank you to Universitas Negeri Padang for providing PNBP funds for this community partnership program in Community Service.

\section{REFERENCES}

[1] Pono Banoe, Kamus Musik, Yogyakarta: Kanisius, 2003.

[2] Pra Budidharma, Pengantar komposisi dan aransemen, Jakarta: Elex Media Komputindo, 2008.

[3] Gordon Delomont, Modern Arranging Technique. New York: Kendor Musik Inc, 1965.

[4] Jamalus dan Hamzah B. Pendidikan kesenian 1. Jakarta: Departemen Pendidikan dan Kebudayaan Direktorat Jenderal Pendidikan Tinggi Proyek Pembinaan Tenaga Kependidikan, 1992.

[5] Genichi Kawakami, Arranging Popular Music, Tokyo: Yamaha Musik Foundation, 1975.

[6] Karl-Edmund Prier S.J., Ilmu Bentuk Musik, Seri A-53, Yogyakarta: Pusat musik Liturgi, 1996.

[7] Hari Purwanto, Music Magic with Noteworthy Composer, Yogyakarta: Andi, 2009.

[8] Gustav Strube, The Theory and Use of Chord-A; Textbook of Harmony. Philadelphia: USA, Oliver Ditson Company. 1975.

[9] Undang-Undang RI No. 20/2003, Sistem Pendidikan Nasional, Jakarta: Departemen Pendidikan Nasional, 2003. 